\title{
Processing Effect on Phytic Acid and Inorganic Phosphorus Content of Soybean (Glycine max, Brown var.)
}

\author{
SOMKANTA RIJAL ${ }^{1,2^{*}}$ and BABITA ADHIKARI ${ }^{2}$ \\ ${ }^{1}$ Department of Food Technology and Quality Control, Kathmandu, Nepal \\ ${ }^{2}$ Central Campus of Technology, Hattisar, Dharan, TU
}

The objective of this research was to study the effect of some processing methods on phytic acid (a prominent anti-nutritive substance) and inorganic phosphorous content of the king legume soybean. The processing treatments viz. soaking and subsequent germination; kinema fermentation and heating were applied. It was observed that soaking for 12 hrs at room temperature under citric acid solution, distilled water and sodium bicarbonate solution significantly $(p<0.05)$ lowered the phytic acid content of soybean by $7.99 \%, 6.38 \%$ and $7.20 \%$ respectively and also correspondingly lowered the inorganic phosphorous by $21.8 \%, 27.55 \%$ and $30.75 \%$. Maximum destruction of phytic acid (35.1\% reduction) occurred during germination for 120 hrs in $0.1 \%$ citric acid solution. This was further confirmed by increase of inorganic phosphorous content (196.22\%) in corresponding treatments. A $46.07 \%$ significant reduction $(p<0.05)$ of phytic acid content over the control was noticed after 72 hrs of kinema fermentation. On the same interval, inorganic phosphorous content also significantly increased by $180 \%$. Autoclaving was found more effective than dry heating and boiling also could reduce the phytic acid content of soybean. Autoclaving (121 ${ }^{\circ} \mathrm{C}$ for $\left.15 \mathrm{~min}\right)$, dry heating $\left(200^{\circ} \mathrm{C}\right.$ for $\left.5 \mathrm{~min}\right)$ and boiling $\left(100^{\circ} \mathrm{C}\right.$ for $\left.30 \mathrm{~min}\right)$ significantly lowered $(p<0.05)$ soybean phytate by $20.76 \%, 12.84 \%$ and $14.84 \%$ respectively. In other hand, inorganic phosphorous content were increased significantly by $80.56 \%$, 43.8\% and $63.55 \%$ at the same time.

Keywords: Soybean, Phytic acid, Phosphorus, Processing effect

\section{Introduction}

One of the noticeable anti-nutritional factor found in soybean is phytic acid. Phytic acid (myoinositol 1, 2, 3, 4, 5, 6-hexakis dihydrogen phosphate) is present in most plant food stuffs as the phytate salt or a complex with protein. In dry soybean seeds, approximately $60-75 \%$ of the phosphorus present is in the form of phytate. Non-ruminant (agastric) animals such as humans, poultry, swine, and fish lack the digestive enzymes necessary for efficient utilization of phytate phosphorus. Besides, phytate removal may be desirable because it potentially forms complexes with minerals and dietary proteins and decreases their bioavailability (Kumar et al., 2010). It also chelates with certain metal ions (such as calcium, zinc, copper and iron) to form insoluble proteinmineral-phytate complexes. These complexes fail to break down readily and make the minerals, especially divalent cations, unavailable (Lönnerdal, 2002). This justifies the need to improve the nutritional value of soybean subdued by the presence of high amount of phytic acid.

Non-ruminants such as poultry, swine, and fish, excrete essentially all feed phytic acid they consume. Undigested phytate excreted in manure could lead to elevated soil phosphorus and the potential for phosphorus runoff into lakes and streams leading to eutrophication and phosphorous pollution (Raboy, 2001). Therefore, strategies to lower phytate levels in animal feed are also of growing interest.

Biological processing techniques, such as soaking, germination, malting, cooking, hydrothermal processing and fermentation, result in the phytate dephosphorylation

\footnotetext{
*Corresponding author, E-mail: rijal.somkanta@gmail.com
}

of the food. Dephosphorylation of phytate in food occurs by increasing the activity of naturally present phytate-degrading enzyme in plants and microorganisms. It must be noted that, during food processing or preparation, phytate is, in general, not completely hydrolyzed by the endogenous phytases of plants and microorganisms. For the optimization of the food process for increased mineral bioavailability by phytate degradation, it is crucial to know optimal conditions of the phytases responsible for phytate degradation. Naturally, there are dissimilarities in the capacities of various plant and microbial species to dephosphorylate phytate, due to differences in their intrinsic phytate-degrading activities (Egli et al., 2002) and the properties of the enzymes, such as protein stability and $\mathrm{pH}$, as well as temperature optimum for phytate degradation (Konietzny and Greiner, 2002).

\section{Materials and Methods \\ Collection and preparation of raw material- The raw material brown variety of soybean (Glycine max) was collected from the local markets of Dharan. The seeds were then cleaned and sorted to remove dust, foreign matters, cracked and damaged seeds. The sound seed samples of about $2 \mathrm{~kg}$ each collected from respected areas were mixed uniformly to obtain a representative lot for the legume. It was then kept in clean air tight container. From this lot, experimental sample units were taken and then subjected to different treatments of the experimental structure in triplicate.}

Collection of Kinema seed culture- Prepared kinema was purchased from the local market of Dharan. It was then grinded into fine powder and inoculated as the seed culture for the kinema fermentation in the lab. 
Soaking treatments- From the stored lot, 200 gram of sound seed sub-sample was weighted out. The seeds were repeatedly washed under tap water and kept in clean plastic tray. The seeds were then soaked in distilled water with seed to water ratio of 1:4. The soaking process was continued for 12 hours with the tray being covered by moist muslin cloth held in place with string. Similarly, by changing the $\mathrm{pH}$ value of soaking medium, the whole procedure was repeated for two more treatments, one being carried out with soaking in $0.1 \%$ citric acid solution ( $\mathrm{pH} 5 \pm 0.2)$ and the other being carried out with soaking in $0.07 \%$ sodium bicarbonate solution $(\mathrm{pH} 8 \pm 0.2$ ). All the seeds sub-samples were soaked with three replicates for 12 hours under three different soaking conditions before sprouting was considered to be underway.

Sprouting and Sampling- After 12 hours, the excess water was drained out of the tray and the treated seeds were rinsed sufficiently with distilled water. The tray was also rinsed and cleaned. The seeds were then again kept in the coded tray, covered with moist muslin cloth and left for sprouting. The seeds were washed with distilled water every 12 hours to reduce any external contamination. All sprouting procedures were carried out at room temperature $\left(27-30^{\circ} \mathrm{C}\right)$, away from direct sunlight under the prevailing light and dark conditions during the day and night respectively.

For the analysis, $25 \mathrm{~g}$ of seed from each treatment structure was harvested after $12 \mathrm{hrs}$ of soaking and also after 24,48 , 72,96 and $120 \mathrm{hrs}$ of germination. The harvested seeds were placed in sealed plastic bags. The seeds were then stored in a freezer at $-5^{\circ} \mathrm{C}$. Freezing the seeds ruptured the seed cell walls because the water in the cells expanded upon freezing. Freezing thus stopped the sprouting sequence. After harvesting of all the treated experimental samples, they were then dried to moisture level below $10 \%$ in the hot air oven at $55 \pm 5^{\circ} \mathrm{C}$. These dried germinated seeds were then grinded into fine powder, passed through 60 mesh screen and stored in sealed plastic bags. Later on, the required sub-samples were weighed and subjected for the individual analysis.

Kinema fermentation and preparation- Kinema was prepared using the seed culture of traditionally made kinema purchased from local market of Dharan. For this, about $500 \mathrm{~g}$ of soybean was cleaned and soaked in tap water for 6 hrs. Excess water was drained after the completion of soaking. Soaked soybeans were autoclaved at $15 \mathrm{psig}$ for $25 \mathrm{~min}$ in autoclave. The seeds were then cooled to temperature around $40^{\circ} \mathrm{C}$. Seeds were then macerated with hands so as to expose the cotyledons from seed coat. About $50 \mathrm{~g}$ of purchased kinema sample was finely ground using mortar and pestle. Inoculation was then carried out by adding powdered kinema at the rate of $3 \%$ with previously prepared soy seeds. The culture was mixed thoroughly and independently with cleaned hands. The inoculated seeds were then incubated at $37^{\circ} \mathrm{C}$ and left for fermentation.
During 24, 48 and 72 hrs of kinema fermentation, samples were harvested, packed in plastic bag and stored in the freezer at $-5^{\circ} \mathrm{C}$. The frozen kinema samples were dried in a cabinet drier at $55 \pm 5^{\circ} \mathrm{C}$ for 10 hour to bring down the moisture content to about $8 \%$. Dried kinema samples were then packed in polythene bags, sealed and stored at ambient condition. $25 \mathrm{~g}$ of each of these prepared kinema samples were taken out, grinded into fine powder in the grinder and analyzed for moisture content, phytic acid content and inorganic phosphorous content in duplicate.

Moist heating- Moist heat treatment was conducted by boiling under atmospheric pressure and by autoclaving. For normal boiling, about $50 \mathrm{~g}$ of the raw seed was taken in borosilicate beaker. The amount of water used for ordinary cooking was three times the weight of the seeds. Seeds were then cooked under boiling water for 30 minutes. Similarly, autoclaving was done by taking about $50 \mathrm{~g}$ of raw seed for 15 minutes at $121 æ \% \mathrm{C}$. The treated seeds were dried in a hot air oven at $55^{\circ} \mathrm{C}$ and grinded into fine powder.

Dry heating- Dry heating was conducted by taking $25 \mathrm{~g}$ of raw seed sample in a clean steel bowl. This was then kept in the OGT (PICASSO 1850) oven maintained at temperature of $200 \pm 5^{\circ} \mathrm{C}$ for a period of 5 minutes. After the treatment the seeds were removed from the oven, cooled and grinded into fine powder.

Analytical methods- Moisture content was determined by drying in electric hot air oven as described in Ranganna (2007). Inorganic phosphorous was determined by the method of Fiske and Subbarow (1925). Phytic acid was determined by the method of Wheeler and Ferrel (1971).

Statistical analysis- For all chemical analysis two replicates of the same sample was used for the determination of each constituent. All experiments were carried out in triplicates. Mean values with standard deviations were computed. Data were subjected to analysis of variance and read at 0.95 confidence level using statistical software GenStat Release 7.1 (Discovery Edition 3 developed by VSN International limited). Fisher's least significant differences (LSD) test was used to define differences between means at the 5\% significance level $(p<0.05)$.

\section{Results and Discussion}

The studied variety showed phytic acid content $1907 \mathrm{mg}$ per 100g dry matter and inorganic phosphorous (iP) content $156.36 \mathrm{mg} / 100 \mathrm{~g}$ dry matter. The estimated values agree with the already published data reviewed by Reddy (2002) and found to be in close range to that reported by Dikshit and Ghadle (2003). Phytate is formed during maturation of plant seeds and so the distribution of phytic acid (myoinositol hexaphosphate) and phosphorous content of legume seed has been reported to vary depending on various factors such 
as variety/cultivars, climatic conditions, location, irrigation conditions, fertilizer application, type of soil and year grown (Deshpande et al., 1982).

Effect of soaking on phytic acid content and inorganic phosphorous content under different $\mathrm{pH}$ conditions- Soaking under $0.1 \%$ citric acid $(\mathrm{pH} 5 \pm 0.2)$, distilled water and $0.07 \%$ sodium bicarbonate solution ( $\mathrm{pH} 8 \pm 0.2)$ significantly $(p<$ 0.05 ) lowered the phytic acid content of soybean to 1754.6 , 1785.2 and $1769.6 \mathrm{mg} / 100 \mathrm{~g}$ respectively $(7.99,6.38$ and $7.2 \%$ reduction). These reduction percentage values are rather low in comparison to that reported by Sattar et al. (1990). Lestienne et al., (2005) have reported a decrease of $23 \%$ of phytic acid during soaking for a period of 24 hours and since we carried out soaking for 12 hours only, a lower reduction was noticed and hence exact comparison could not be made. They also reported a net increase of inorganic phosphorous in soybean seed by $36.23 \%$ in their study. In contrast a significant ( $p$ $<0.05$ ) decrease of inorganic phosphorous (iP) by $21.8 \%$, $27.55 \%$ and $30.75 \%$ was observed during soaking in $0.1 \%$ citric acid, distilled water and $0.07 \%$ sodium bicarbonate respectively. This may be due to comparatively short soaking period during which the activity of endogenous phytase might be low enough to liberate significant inorganic phosphorous and hence diffusion of inorganic phosphorous in soaking water exceeded its liberation inside the seed. These observations have been shown in Figure 1, where bars in the same cluster with different top labels are significantly different at $5 \%$ level of significance. Moreover, in the present study, the presence of acid and alkali during soaking had no significant effect $(p<$ 0.05 ) in lowering the phytic acid and inorganic phosphorous content of soybean.

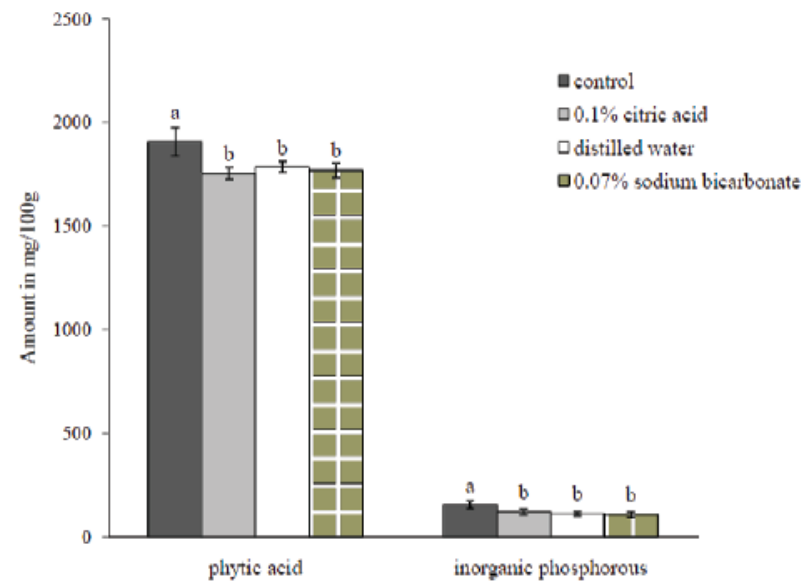

Figure 1. Effect of soaking under different condition on phytic acid and inorganic phosphorous

Germination effect on phytic acid- During germination period of $120 \mathrm{hrs}$, the phytic acid content significantly decreased at each successive $24 \mathrm{hrs}$ interval to $1649.4,1561.3,1471.4$, 1383.2 and $1237 \mathrm{mg} / 100 \mathrm{~g}$ for soaking under $0.1 \%$ citric acid solution (13.5 - 35.13\% reduction); to $1665.2,1587.2,1491$, 1410.6 and $1303.3 \mathrm{mg} / 100 \mathrm{~g}$ for soaking in distilled water (12.68 - 31.65\% reduction) and to $1686.2,1594.6,1506.5$,
1420.3 and 1319.6 for soaking in $0.07 \%$ sodium bicarbonate solution (11.58 - 30.8\% reduction). All these reduction values are within the range reviewed by Sathe and Venkatachalam (2002).

The phytic acid degradation enhanced with increasing germination time and its reduction value was observed more in $0.1 \%$ citric acid ( $\mathrm{pH} 5 \pm 0.2)$. Mean value of phytate destruction was significantly greater $(p<0.05)$ during germination under acidic soaking condition ( $\mathrm{pH} 5 \pm 0.2)$ as compared to germination under neutral $(\mathrm{pH} 7)$ and alkaline $(\mathrm{pH} 8 \pm 0.2)$ soaking conditions. However, the mean destruction level of phytic acid was non-significant $(p<0.05)$ for germination under neutral and alkaline soaking condition. In case of phytate degradation, no significant interaction was found between soaking $\mathrm{pH}$ and germination time.

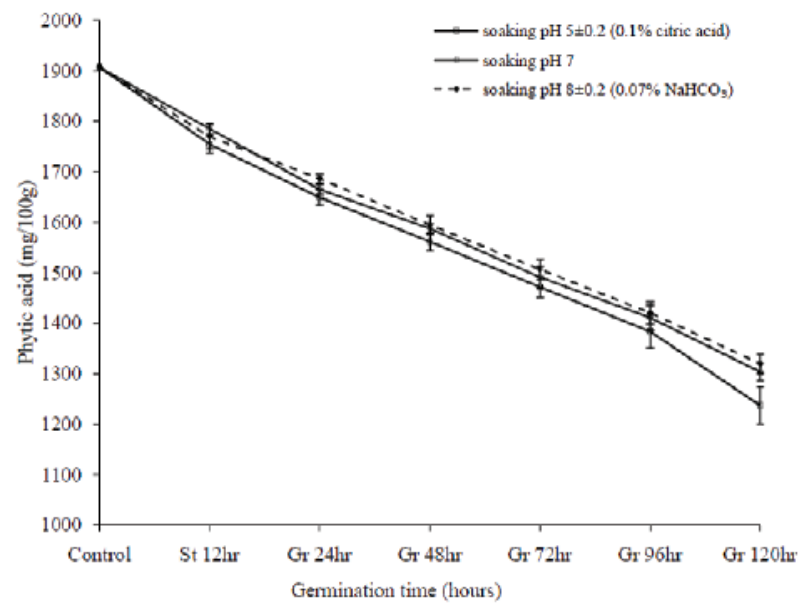

Figure 2. Effect of soaking $\mathrm{pH}$ and germination time on phytic acid content of soybean

Germination effect on inorganic phosphorous- During the germination period of 120 hours, the inorganic phosphorous content significantly increased at each successive 24 hours intervals to $182,233.3,305.3,395.3$ and $463.3 \mathrm{mg} / 100 \mathrm{~g}$ for soaking in $0.1 \%$ citric acid, to $165.7,198,270.3,380.7$ and $436 \mathrm{mg} / 100 \mathrm{~g}$ for soaking in distilled water and to the level of $155.3,205.3,260.3,373$ and $429.7 \mathrm{mg} / 100 \mathrm{~g}$ for soaking in $0.07 \%$ sodium bicarbonate. All these increment values are in accordance to the destruction trend of phytic acid. It has been suggested that $\mathrm{pH}$ value also seems to play a role in the activity of endogenous phytase. According to the literature, $\mathrm{pH}$ optima for most plant phytase activities (including soybean) range from 4.6 to 6.0 (Honke et al., 1999). During germination phytase enzyme is activated which hydrolyses the phytic acid into lower inisitol phosphates and liberates inorganic phosphorous. Thus, the relative decrease in phytate should be accompanied by the concomitant increase in inorganic phosphorous content and trend was also observed accordingly. 


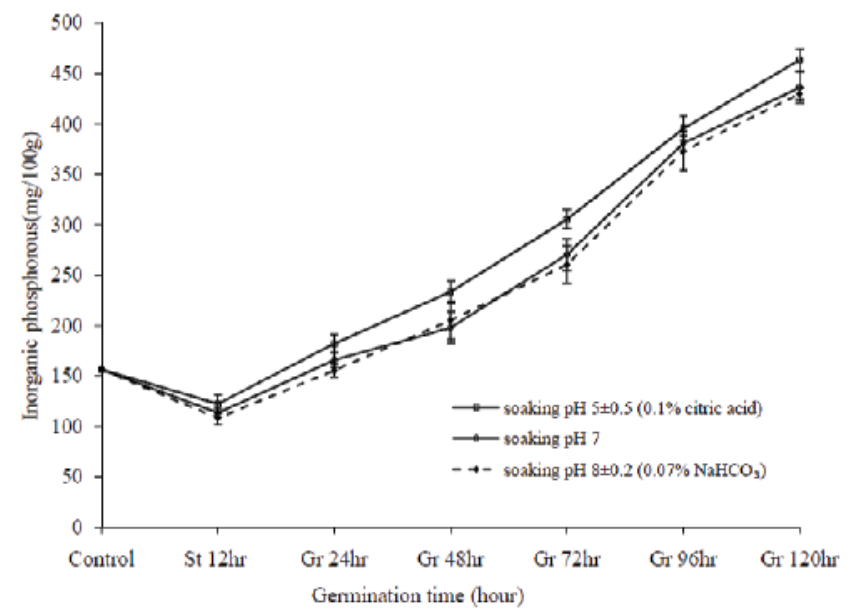

Figure 3. Changes in inorganic phosphorous content of soybean in relation to soaking $\mathrm{pH}$ and germination time

The observed data were analyzed statistically, which indicated significant effect of soaking $\mathrm{pH}$ and germination time on phytate content and on inorganic phosphorous content $(p<$ $0.01)$. However, no significant interaction was found between soaking $\mathrm{pH}$ and germination time. Hence, we could safely conclude the phytic acid content of soybean decreases with the increase in germination time as well as greater destruction of phytate occurs in acidic ( $\mathrm{pH} 5 \pm 0.2$ ) soaking environment. The same is the case for inorganic phosphorous except that it follows the increasing trend. Faster degradation of phytate during germination by soaking at acidic soaking condition could be attributed to the higher activity of intrinsic phytase which has optimal pH value around 4.5 - 4.8 (Gibson and Ullah, 1988).
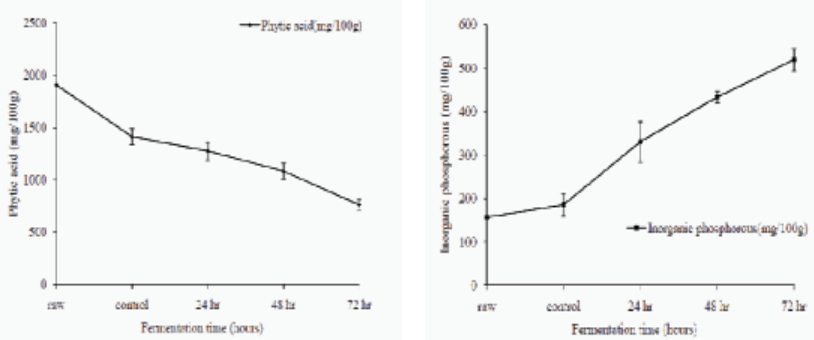

Figure 4. Changes in phytic acid and inorganic content of soybean during kinema fermentation

Effect of kinema fermentation on phytic acid and inorganic phosphorous content of soybean- A $9.69 \%$ significant ( $p$ $<0.5$ ) reduction of phytic acid content over the control was noticed after 24 hours of kinema fermentation and this reduction rose to the level of $23.21 \%$ and $46.07 \%$ after 48 hrs and 72 hrs respectively. On the other hand, inorganic phosphorous content also significantly increased by $78.25 \%$, $133.5 \%$ and $180 \%$ corresponding to the fermentation period of 24, 48 and $72 \mathrm{hrs}$ respectively. These trends have been depicted in Figure 4. Since the endogenous phytase enzyme was completely destroyed during autoclaving, the reduction in phytic acid content could be attributed solely due to microbial effect. This proves that microbes are also capable of producing phytase enzyme that could hydrolyze phytic acid of plant origin. The enzymatic reduction on phytic acid content is further confirmed by simultaneous increase of inorganic phosphorous content.

A wide range exists in phytate reduction value proposed by different researchers during soybean fermentation. Marfo et al., (1990) and Chitra et al., (1996) reported the reduction value of phytate during fermentation by $61.5 \%$ and $32.33 \%$ in their research. The difference in the culture inoculums might produce varying levels of phytase activity and subsequent variation in the extent to which phytic acid is hydrolyzed in the product.

Effect of heat treatments on phytic acid and inorganic phosphorous content of soybean- Both wet heating and dry heating treatment significantly ( $p \mathrm{~d}$ " 0.05 ) reduced the phytic acid content of soybean along with concomitant increase in inorganic phosphorous. Boiling under normal atmospheric pressure for period of 30 minutes lowered the soybean phytate by $14.84 \%$ with simultaneous increase in iP by $63.55 \%$. Autoclaving for $15 \mathrm{~min}$ at $121^{\circ} \mathrm{C}$, on the other hand, reduced soybean phytate by $20.76 \%$ and simultaneously increased iP content by $80.56 \%$. Likewise, dry heating of soybean at $200^{\circ} \mathrm{C}$ reduced its phytic acid content by $12.84 \%$ and concomitantly increased iP by $43.8 \%$. The phytate reduction values for autoclaving and dry heating are slightly lower than those reviewed by Sathe and Venkatachalam (2002). But, for boiling treatment, the reduction value of phytic acid is in agreement with the review of Sathe and Venkatachalam (2002).

Destruction of phytate during cooking is mainly due to the leaching into the hot cooking water.

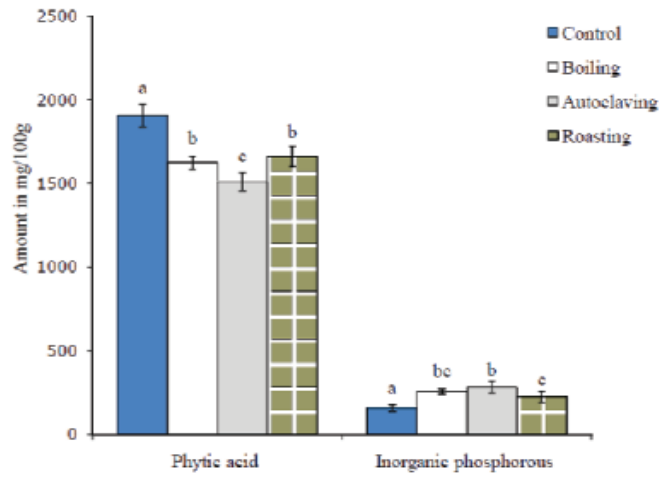

Figure 5. Impact of different heat treatment methods on phytic acid and inorganic phosphorous

According to Boland et al., (1975), the differences in the loss of phytic acid contents during cooking could probably be explained on the basis that phytase activity at a temperature of $40-55^{\circ} \mathrm{C}$ may degrade inositol hexaphosphate to the pentaphosphate or lower molecular weight forms. 


\section{Conclusion}

It was found that soaking, germination, kineama fermentation and cooking methods have different efficacies in reducing phytic acid and increasing inorganic phosphorous content of soybeans. Decreases caused by fermentation and germination are mainly based on the action of enzymes while, in soaking and cooking, a combination of diffusion and enzymatic action is expected (Henderson and Ankrah, 1985; de Boland et al., 1975). Overall, although a complete removal of phytic acid was not observed, all the different processing and cooking methods were found to be beneficial for lowering the phytic acid content and improving the bioavailability of dietary essential minerals in soybean. Among all methods, kinema fermentation was found to be the best method, followed by germination (under acidic soaking condition), pressure cooking, ordinary cooking, dry heating and soaking of the soybean seeds. Hence, for proper utilization of soybean, especially in developing countries, these simple and economic household processing and cooking methods should be followed, as they not only save time, energy and fuel consumption but also enhance the nutritional quality of the legumes by lowering the content of antinutrients and increasing the bioavailability of minerals.

\section{References}

Chitra U., Singh U. and Rao P. V. (1996). Phytic acid, in vitro protein digestibility, dietary fiber and minerals of pulses as influenced by processing methods. Plant Foods for Human Nutr., 49, 307-316.

de Boland A. R., Garner G. B. and O'dell B.L. (1975). Identification and properties of phytate in cereal grains and oil seed products. J. Agric. Food Chem., 23, 11861190.

Deshpande S. S., Sathe S. K., Salunkhe D. K. and Cornforth, D.P. (1982). Effect of dehulling on phytic acid, polyphenols, and enzyme inhibitors of dry beans. J. Food Sci., 47, 1846.

Dikshit M. and Ghadle M. (2003). Effect of sprouting on nutrients, antinutrients and in vitro digestibility of the MACS-13 soybean variety. Plant Foods for Human Nutr., 58, 1-11.

Egli I., Davidsson L., Juillerat M. A., Barclay D. and Hurrell R. F. (2002). The influence of soaking and germination on the phytase activity and phytic acid content of grains and seeds potentially useful for complementary feeding. J. Food Sci., 67: 3484-3488.

Fiske C. H. and Subbarow Y. (1925). Colorimetric determination of Phosphorus. J. Biol Chem., 66:375.

Gibson D. M. and Ullah A. H. J. (1988). Purification and characterization of phytase from cotyledons of germinating soybean seeds. Arch. Biochem. Biophys., 260: 503-513.
Henderson H. M. and Ankrah S. A. (1985). The relationship of endogenous phytase, phytic acid and moisture uptake with cooking time in Vicia faba minor cv. Aladin. Food Chem., 17:1-11.

Honke J., Sandberg A. S. and Kozlowska H. (1999). The influence of $\mathrm{pH}$ and temperature on the endogenous phytase activity and on hydrolysis of inositol hexaphosphate in lentil, faba bean and pea seeds. Polish J. Food Nutr. Sci., 49: 109-122.

Konietzny U. and Greiner R. (2002). Molecular and catalytic properties of phytatedegrading enzymes (phytases). International Journal of Food Science and Technology, 37:791-812.

Kumar V., Sinha A. K., Makkar H. P. S. and Becker K. (2010). Dietary roles of phytate and phytase in human nutrition: a review. Food Chem., 120: 945-959.

Lestienne I., Mouquet C., Icard-Vernie're C., Rochette I. and Tre'che S. (2005). The effect of soaking of whole, dehulled and ground millet and soybean seeds on phytate degradation and phy/Fe and phy/Zn molar ratio. Int. J. of Food Sci. and Techn., 40: 391-399.

Lönnerdal B. (2002). Phytic acid-trace element (Zn, Cu, Mn) interactions. Inter. J. Food Sci. and Tech., 37:749-758.

Marfo E. K., Simpson B. K., Idowu J. S. and Oke O. L. (1990). Effect of local processing on phytate levels on cassava, cocoyam, yam, maize, sorghum, rice, cowpea and soybean. J. Agric. Food Chem., 38:1580-1585.

Raboy V. (2001). Seeds for a better future: Low phytate grains help to overcome malnutrition and reduce pollution. Trends in Plant Science, 6: 458-462.

Ranganna S. (2007). Handbook of Analysis and Quality Control for Fruit and Vegetable Products. 2nd edn. Tata McGraw-Hill Pub., New Delhi, pp 3-5, 125-126.

Reddy N. R. (2002). Occurrence, distribution, content, and dietary intake of phytate. In: Food phytates, (N. R. Reddy \& S. K. Sathe, eds), pp. 25-51. Boca Raton, Florida: CRC Press.

Sathe S. K. and Venkatachalam M. (2002). Influence of processing technologies on phytate and its removal. In: Food Phytates. (N.R. Reddy \& S. K. Sathe, eds.), pp. 150-181. Boca Raton, Florida: CRC Press.

Sattar A., Neelofar and Akhtar M. A. (1990). Effect of radiation and soaking on phytate content of soybean. Acta. Aliment. Hung., 19: 331-336.

Wheeler E. L. and Ferrel R. E. (1971). A method for the determination of phytic acid in wheat and wheat fractions. Cereal Chem., 48: 313-320. 